\title{
CONDIÇÕES DE PRODUÇÃO VOCAL DE PROFESSORES DA REDE MUNICIPAL DE CAMPINAS
}

\section{Ana Carolina Constantini, Giselle C. Said*.}

\section{Resumo}

Problema ambiental, a poluição sonora tem se destacado por influenciar a saúde física e mental do indivíduo. Concomitante, a ausência de noções básicas sobre voz e seu uso incorreto podem gerar problemas vocais em professores, que acabam apresentando queixas devido ao seu trabalho, ocasionadas, também, por ruídos diversos.

\section{Palavras-chave: \\ Voz, Professor, Distúrbio de Voz}

\section{Introdução}

Além de desempenhar papel fundamental na comunicação humana, a voz permeia significativamente as relações de subsistência de muitas categorias profissionais, que dependem de uma boa produção vocal para satisfazer suas demandas de trabalho ${ }^{2}$. Dentre os profissionais que se utilizam intensamente da voz, o professor é o que apresenta maior ocorrência de distúrbio vocal por nem sempre dispor de condições favoráveis de trabalho.

\section{Resultados e Discussão}

Professores do Distrito Norte de Campinas foram selecionados, após cálculo estatístico, para constituição de amostra representativa de participantes.

Os dados coletados foram organizados em planilha Excel e a seguir submetidos à análise descritiva e inferencial. Por meio do teste de Qui-quadrado e teste exato de Fisher foi analisada a associação entre as variáveis. A variável dependente foi a presença do distúrbio de voz (calculada a partir do instrumento Índice de Triagem do Distúrbio de Voz - ITDV) inserido no CPV-P, que considera ter provável Distúrbio Vocal os que assinalam, nas frequências às vezes e sempre, cinco ou mais sintomas. Foram analisados 64 professores que lecionam, em média, há 22,63 anos. A frequência de Distúrbio Vocal (DV) entre os professores foi de $47,6 \%$, sem diferença entre professores de ensino infantil e fundamental. Encontrou-se associação estaticamente significativa entre a presença de DV e o ruído presente na escola $(57,81 \%)$, ruído presente em sala de aula $(60,93 \%)$, e o volume produzido por estes sons $(39 \%)$. Dentre a análise de dados encontradas, os dados que mais chamam a atenção em porcentagem de periodicidade encontram-se mostrados na tabela 1 a seguir.

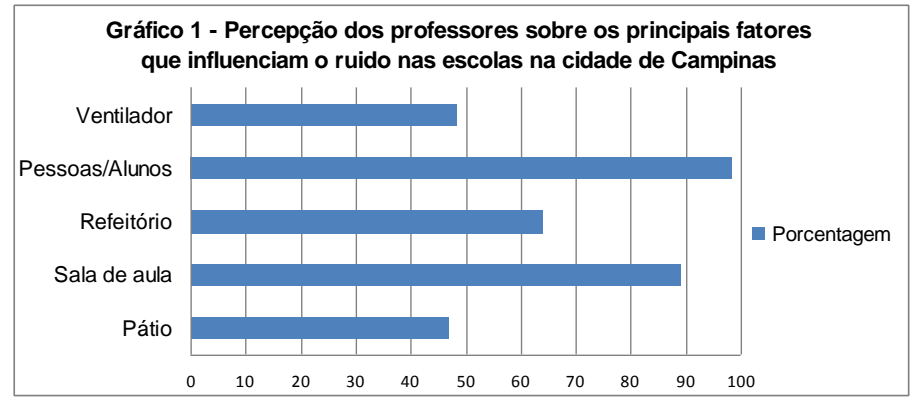

Tabela 1. Análise de queixas de ruído estruturais.

\begin{tabular}{|c|c|c|}
\hline Questão & $\begin{array}{c}\text { Periodicidade } \\
\text { - Sempre }\end{array}$ & $\begin{array}{c}\text { Periodicidade - } \\
\text { Às vezes }\end{array}$ \\
\hline Escola Ruidosa & $57,81 \%$ & $37,5 \%$ \\
\hline $\begin{array}{c}\text { Sala de Aula } \\
\text { Ruidosa }\end{array}$ & $60,93 \%$ & $31,25 \%$ \\
\hline $\begin{array}{c}\text { Ruído } \\
\text { Observado é } \\
\text { Alto }\end{array}$ & $39 \%$ & $56,25 \%$ \\
\hline \multicolumn{3}{|c|}{ Conclusões } \\
\hline
\end{tabular}

Os resultados encontrados vão ao encontro de achados da literatura nacional e internacional, com discreta diminuição da presença de DV em Campinas. A análise permite concluir que, quaisquer que sejam os ruídos, eles interferem na qualidade vocal e de vida do professor, necessitando ausentar-se no trabalho, o que também gera prejuízos econômicos. Diante disso, devese manter o olhar integral a essa categoria profissional, bem como a continuidade de pesquisas que possam auxiliar no planejamento de ações de prevenção e promoção de saúde e de hábitos vocais saudáveis junto a essa população.

\section{Agradecimentos}

Agradeço ao PIBIC pela oportunidade em realizar este trabalho e à Prefeitura Municipal de Campinas pela parceria e apoio à pesquisa.

${ }^{1}$ Nascimento, Ludimila Souza; Lemos, Stela Maris Aguiar. A Influência do Ruído Ambiental no Desempenho de Escolares nos Testes de Padrão Tonal de Frequência e Padrão Tonal de Duração. Ver. CEFAC, 2012 Mai-Jun; 14(3): 390-402.

${ }^{2}$ Silva, Gislayne Januaria de; Almeida, Anna Alice; Lucena, Brunna Thaís Luckwu de; Silva, Maria Fabiana Bonfim de Lima. Sintomas Vocais e as causas autorreferidas em professores. Ver. CEFAC, 2016. 